Article

\title{
Interactions of Small-Molecule Guests with Interior and Exterior Surfaces of a Coordination Cage Host
}

\author{
Christopher G. P. Taylor ${ }^{1}\left(\mathbb{D}\right.$, Jennifer S. Train ${ }^{2}$ and Michael D. Ward ${ }^{1, *(\mathbb{D})}$ \\ 1 Department of Chemistry, University of Warwick, Coventry CV4 7AL, UK; C.Taylor.10@warwick.ac.uk \\ 2 Department of Chemistry, University of Sheffield, Western Bank, Sheffield S3 7HF, UK; \\ jennifer.train@kcl.ac.uk \\ * Correspondence: m.d.ward@warwick.ac.uk
}

Received: 15 May 2020; Accepted: 1 June 2020; Published: 2 June 2020

\begin{abstract}
Coordination cages are well-known to act as molecular containers that can bind small-molecule guests in their cavity. Such cavity binding is associated with interactions of the guests with the surrounding set of surfaces that define the cavity; a guest that is a good fit for the cavity will have many favourable interactions with the interior surfaces of the host. As cages have exterior as well as interior surfaces, possibilities also exist for 'guests' that are not well-bound in the cavity to interact with the exterior surface of the cage where spatial constraints are fewer. In this paper, we report a combined solid-state and solution study using an octanuclear cubic $\mathrm{M}_{8} \mathrm{~L}_{12}$ coordination cage which illustrates the occurrence of both types of interaction. Firstly, crystallographic studies show that a range of guests bind inside the cavity (either singly or in stacked pairs) and/or interact with the cage exterior surface, depending on their size. Secondly, fluorescence titrations in aqueous solution show how some flexible aromatic disulfides show two separate types of interaction with the cage, having different spectroscopic consequences; we ascribe this to separate interactions with the exterior surface and the interior surface of the host cage with the former having a higher binding constant. Overall, it is clear that the idea of host/guest interactions in molecular containers needs to take more account of external surface interactions as well as the obvious cavity-based binding.
\end{abstract}

Keywords: coordination cage; host-guest chemistry; fluorescence; crystal structures; supramolecular chemistry

\section{Introduction}

As part of the study of coordination cages-hollow, self-assembled metal-ligand capsules-there is a great deal of emphasis on guest binding in the internal space [1-29]. Functions such as catalysis [6-12], substrate transport [13-16], sensing [17] and enantioselective recognition and separation [18] are all based around guest binding inside the host cage, and consequently, a huge amount of work exists on the study of cage-based host/guest interactions. This includes the synthesis of cages that are engineered with interior binding sites to facilitate guest binding [19,20]; quantification of guest binding constants and analysis of the factors responsible for guest binding [21-24] including co-encapsulation of multiple guests [25-27]; and studies of how specific guests act as templates for host cage assembly [28,29].

Despite this focus almost exclusively on the cages' interior spaces, more recently, attention has started to turn to their exterior surfaces, which may also possess the ability to interact with small-molecule guests. The cages reported from our group often-in addition to accommodating guests inside the cavities-bind anions in the 'windows' on cage surfaces, in regions close to metal cations where a large number of $\mathrm{CH} \cdots \mathrm{X}^{-}$hydrogen bonds can form between the cage surface and anions $\mathrm{X}^{-}$[30,31]. Nitschke [32] and Raymond [33] have likewise demonstrated interaction of small molecules or counter-ions with cage exterior surfaces. 
It is almost a statement of the extremely obvious to point out that cage-based host/guest chemistry is not about the cage cavity per se but is really about the disposition of the interior surfaces which define the cavity. When guests bind inside a cage cavity, the cage/guest interactions responsible for the binding are interactions of the guest with the cage interior surfaces, whether they are hydrogen-bonding, van der Waals' or hydrophobic interactions, and will be maximised when the guest size and shape are a good match for the cavity such that host and guest surfaces are complementary. However, these interior surfaces will be matched by chemically similar exterior surfaces which inevitably have a larger surface area. It follows that any small molecule/surface interactions that are responsible for guest binding inside a cavity could equally well apply to interactions with the exterior surface, so even if the guest is not a good shape/size match for the interior cavity, favourable interactions with the cage exterior are still possible. The number of favourable contacts will necessarily be smaller as the guest is not perfectly encapsulated, but the larger surface area of the cage exterior compared to its interior will mitigate this to some extent.

In our own recent research, we have identified examples of cage-based catalysis between neutral substrates interacting with the cage by the hydrophobic effect, and anions attracted to the cage surface via ion-pairing effects [31,34-36]. The most effective catalysis (examples of the Kemp elimination) occurs with the cavity-bound guest benzisoxazole, as shown by the fact that blocking the cage cavity with an inert inhibitor and displacing the benzisoxazole stops catalysis in this case [34]. However less dramatic-but still significant-catalysis occurs at the cage exterior surface in the case of (i) hydrolysis of phosphotriesters which bind only weakly or not at all in the cage cavity [35], and (ii) the aldol self-condensation of indane-1,3-dione [36]. In both of these cases, preventing the guest from entering the cage cavity by blocking the cavity with a competing inhibitor makes no difference to the catalysis rate. We have also noticed in our structural studies of cage/guest assembles that, in a few cases, 'guest' molecules in the crystal lattice can occupy positions in the lattice outside the cage cavities that allow them to interact with cage exterior surfaces as well as occupying the cage cavities [35-37].

A clear picture is emerging that the exterior surfaces of cages, and their interactions with guests, may be just as important as the cavity-based binding of guests which has been the dominant focus of cage-based host/guest chemistry. In this paper, we present a combined structural and solution study that extends this principle further, with a set crystal structures of host/guest complexes based on our $\mathrm{M}_{8} \mathrm{~L}_{12}$ cubic host cage which show either interior, or exterior, guest binding (or both); and a set of solution spectroscopic titrations showing two-step behaviour which can be ascribed to distinct cavity-based and external surface-based guest binding events.

\section{Materials and Methods}

The Co(II)-based cages $\mathbf{H}$ (as the tetrafluoroborate salt) [38], $\mathbf{H}^{\mathrm{Co}}$ (as the chloride salt) [31] and the isostructural Cd(II) cage $\mathbf{H}^{\mathrm{Cd}}$ [39] (see main text for definitions of these abbreviations) were prepared as previously described. All organic guest species were purchased from Sigma-Aldrich (Gillingham, UK). Instrumentation used for routine spectroscopic measurements was as follows: ${ }^{1} \mathrm{H}-\mathrm{NMR}$ spectroscopy, a Bruker Avance $400 \mathrm{MHz}$ instrument; fluorescence spectra, a Horiba Jobin-Yvon Fluoromax 4 instrument (Northampton, UK). ${ }^{1} \mathrm{H}$ NMR titrations and fluorescence titrations used to evaluate cage/guest binding were performed as described in previous papers $[21,22,39,40]$. Molecular volumes were calculated with SPARTAN18 [41].

The X-ray crystallographic data for the five cage/guest complexes reported in this paper were collected in Experiment Hutch 1 of beamline I-19 at the UK Diamond Light Source synchrotron facility [42] using the automatic sample-changing robot [43]. Full details of the instrumentation, methods used for data collection, and software used for the solution and refinement of the structures, are as recently published [37]. Crystallographic, data collection and refinement parameters are collected in Table 1 (see CIF for details, Supplementary Materials). CCDC deposition numbers: 2006973-2006977. 
Table 1. Summary of crystallographic, data collection and refinement parameters for the five crystal structures in this paper.

\begin{tabular}{|c|c|c|}
\hline Guest & Di(2-pyridyl)disulfide & 3,4,5,6-Tetrachloro-1,2-benzoquinone \\
\hline Empirical formula & $\begin{array}{c}\mathrm{C}_{378.65} \mathrm{H}_{417.32} \mathrm{~B}_{16} \mathrm{Co}_{8} \mathrm{~F}_{64} \mathrm{~N}_{73.08} \\
\mathrm{O}_{37.25} \mathrm{~S}_{1.08}\end{array}$ & $\mathrm{C}_{377} \mathrm{H}_{416} \mathrm{~B}_{16} \mathrm{Cl}_{2} \mathrm{Co}_{8} \mathrm{~F}_{64} \mathrm{~N}_{72} \mathrm{O}_{39}$ \\
\hline Formula weight & 8483.10 & 8511.09 \\
\hline$T / K$ & $100(1)$ & $100(1)$ \\
\hline Crystal system & Monoclinic & Monoclinic \\
\hline Space group & $\mathrm{C} 2 / \mathrm{c}$ & $\mathrm{C} 2 / \mathrm{c}$ \\
\hline Crystal size $/ \mathrm{mm}^{3}$ & $0.1 \times 0.1 \times 0.1$ & $0.1 \times 0.1 \times 0.1$ \\
\hline$a / \AA$ & $32.81236(7)$ & $32.85880(17)$ \\
\hline$b / \AA$ & $30.21497(6)$ & $30.06718(13)$ \\
\hline$c / \AA$ & $40.09564(8)$ & $40.1053(2)$ \\
\hline$\beta /$ degrees & 96.33120(19) & $96.0585(5)$ \\
\hline$V / \AA^{3}$ & $39509.35(10)$ & $39401.6(3)$ \\
\hline Z & 4 & 4 \\
\hline$\rho_{\text {calc }} / \mathrm{g} \mathrm{cm}^{-3}$ & 1.426 & 1.435 \\
\hline$\mu / \mathrm{mm}^{-1}$ & 0.410 & 0.415 \\
\hline Radiation & Synchrotron $(\lambda=0.6889)$ & Synchrotron $(\lambda=0.6889)$ \\
\hline Reflections collected & 348244 & 341329 \\
\hline Data/restraints/parameters & $62856 / 6404 / 2425$ & $62724 / 5560 / 2167$ \\
\hline Final $R$ indexes $[I \geq 2 \sigma(I)]$ & $R_{1}=0.0672, \mathrm{w} R_{2}=0.2167$ & $R_{1}=0.0829, \mathrm{w} R_{2}=0.2810$ \\
\hline Final $R$ indexes (all data) & $R_{1}=0.0926, \mathrm{w} R_{2}=0.2358$ & $R_{1}=0.1178, \mathrm{w} R_{2}=0.3061$ \\
\hline 7-Methoxycoumarin & 2-Methylacetophenone & 2-Methoxyacetophenone \\
\hline $\mathrm{C}_{376} \mathrm{H}_{392} \mathrm{~B}_{16} \mathrm{Co}_{8} \mathrm{~F}_{64} \mathrm{~N}_{72} \mathrm{O}_{33}$ & $\begin{array}{c}\mathrm{C}_{407.8} \mathrm{H}_{417.66} \mathrm{~B}_{16} \mathrm{Co}_{8} \mathrm{~F}_{64} \mathrm{~N}_{72} \\
\mathrm{O}_{31.03}\end{array}$ & $\mathrm{C}_{395.5} \mathrm{H}_{411} \mathrm{~B}_{16} \mathrm{Co}_{8} \mathrm{~F}_{64} \mathrm{~N}_{72} \mathrm{O}_{35}$ \\
\hline 8307.99 & 8684.25 & 8593.34 \\
\hline $100(1)$ & $100(1)$ & $100(1)$ \\
\hline Monoclinic & Monoclinic & Monoclinic \\
\hline $\mathrm{C} 2 / \mathrm{c}$ & $\mathrm{C} 2 / \mathrm{c}$ & $\mathrm{C} 2 / \mathrm{c}$ \\
\hline $0.15 \times 0.12 \times 0.1$ & $0.04 \times 0.03 \times 0.03$ & $0.04 \times 0.04 \times 0.04$ \\
\hline $33.04596(13)$ & $32.56923(10)$ & $32.8649(2)$ \\
\hline $30.13654(16)$ & $30.16165(10)$ & $29.89225(18)$ \\
\hline $39.97965(19)$ & $40.83634(17)$ & $40.5389(4)$ \\
\hline $96.4337(4)$ & $95.9061(3)$ & $95.9164(7)$ \\
\hline $39564.3(2)$ & 39902.31(19) & $39613.5(4)$ \\
\hline 4 & 4 & 4 \\
\hline 1.395 & 1.446 & 1.441 \\
\hline 0.398 & 0.398 & 0.401 \\
\hline Synchrotron $(\lambda=0.6889)$ & Synchrotron $(\lambda=0.6889)$ & Synchrotron $(\lambda=0.6889)$ \\
\hline 344542 & 346719 & 337691 \\
\hline $62978 / 6651 / 2517$ & $63534 / 7141 / 2727$ & $63039 / 6014 / 2426$ \\
\hline$R_{1}=0.0719, \mathrm{w} R_{2}=0.2392$ & $R_{1}=0.0827, \mathrm{w} R_{2}=0.2704$ & $R_{1}=0.0853, \mathrm{w} R_{2}=0.2817$ \\
\hline$R_{1}=0.0971, \mathrm{w} R_{2}=0.2596$ & $R_{1}=0.1201, \mathrm{w} R_{2}=0.2981$ & $R_{1}=0.1351, \mathrm{w} R_{2}=0.3169$ \\
\hline
\end{tabular}




\section{Results}

\subsection{The Cage Hosts}

The set of host/guest structures we report here is based on the octanuclear cubic cage $\left[\mathrm{Co}_{8} \mathrm{~L}_{12}\right]\left(\mathrm{BF}_{4}\right)_{16}$ (abbreviated as $\mathbf{H}$, for 'host') that we have studied extensively [21-24,30,31,34-40] (Figure 1). It has a cavity volume of $409 \AA^{3}$ [37]. We have found that the best way to introduce guests into the cavity to give single crystals of the adducts is to use the 'crystalline sponge' methodology pioneered by Fujita [44,45], in which we pre-prepare a batch of single crystals of the cage whose cavity is empty apart from solvent molecules, and immerse a crystal in a concentrated solution of the guest for several hours. In a significant number of cases, guests are taken up into the crystals without loss of crystallinity and the structure of the cage/guest complex can be determined $[22,36,37,40]$.

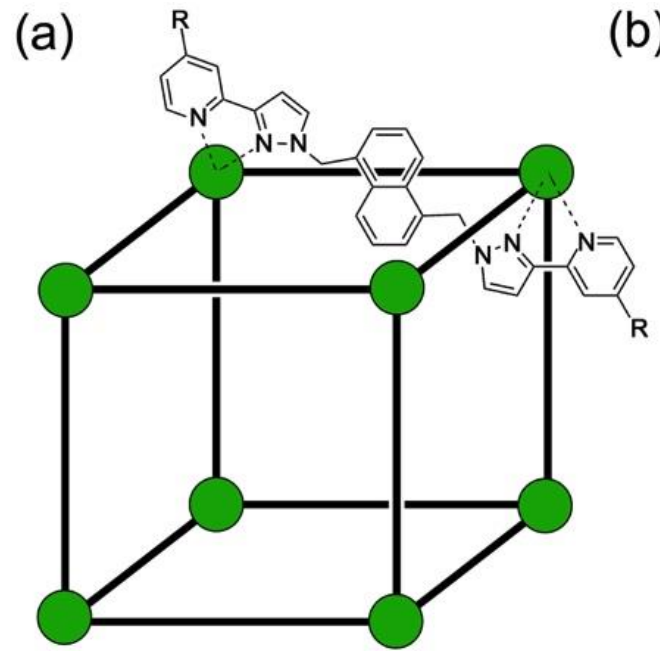

(b)

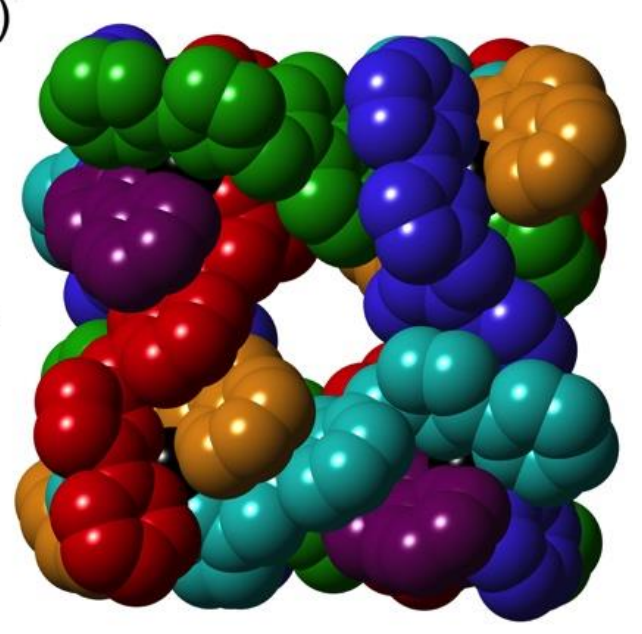

Figure 1. The octanuclear $\left[\mathrm{Co}_{8} \mathrm{~L}_{12}\right]\left(\mathrm{BF}_{4}\right)_{16}$ cages used in this work $\left(\mathrm{H}, \mathrm{R}=\mathrm{H}\right.$ [38]; $\left.\mathbf{H}^{\mathbf{w}}, \mathrm{R}=\mathrm{CH}_{2} \mathrm{OH},[21]\right)$. (a) A sketch showing the approximate arrangement of metal ions and the structural formula of the bridging ligands, which span every edge of the cubic array of $\mathrm{Co}(\mathrm{II})$ ions; (b) a view of the cationic cage cavity with each ligand coloured separately.

\subsection{Structures of Cage/Guest Complexes}

The first example we describe is the complex of $\mathbf{H}$ with di(2-pyridyl)disulfide $\left(\mathbf{G}^{2 \mathbf{P y}}\right)$ which we were interested in because of the possibility of cage-to-guest photoinduced electron transfer in the complex [39,40]; views of the structure are shown in Figures 2 and 3. The guest is folded up inside the cavity with a C-S-S-C torsion angle of $76^{\circ}$, and the two pyridyl rings on the same side of the disulfide bond, affording the typical skewed chiral conformation [46]; Figure 2 shows a space-filling view of the guest inside a wireframe view of the cage. As is usual with a guest bound inside this cage, the guest is anchored by a collection of weak hydrogen-bonding interactions between the electron-rich $S$ atom and a convergent set of inwardly-directed $\mathrm{CH}$ protons associated with the fac tris-chelate vertices, in a region of high positive electrostatic potential [47]. Thus, $\mathrm{S}(17 \mathrm{G})$ forms $\mathrm{CH} \cdots \mathrm{S}$ interactions with $\mathrm{H}(54 \mathrm{C})$ $(2.82 \AA), \mathrm{H}(46 \mathrm{~F})(3.08 \AA)$ and $\mathrm{H}(61 \mathrm{D})(3.12 \AA)$ as well as several longer interactions; and the adjacent pyridyl ring $\mathrm{N}$ atom $\mathrm{N}(11 \mathrm{G})$ likewise forms some short $\mathrm{CH} \cdots \mathrm{N}$ contacts with, e.g., $\mathrm{H}(54 \mathrm{~F})(2.59 \AA)$ and $\mathrm{H}(54 \mathrm{C})(2.90 \AA$ ) (Figure 3). The equivalent H-bonding pocket at the diagonally opposite corner of the cage interior surface contains two $\mathrm{MeOH}$ molecules which likewise form $\mathrm{CH}$ ‥ O interactions with the cage interior surface. The two pockets are crystallographically equivalent-there is an inversion centre in the cage/guest assembly—such that the content of the two binding pockets (one $\mathrm{G}^{2 \mathrm{Py}}$ guest, or a pair of $\mathrm{MeOH}$ molecules) are disordered over both sites. As often happens in crystalline sponge experiments, the occupancy of the cage cavity is not complete: the site occupancy of $\mathbf{G}^{2 \mathbf{P y}}$ is 0.28 per 
asymmetric unit ( 0.56 per complete cage), and the two $\mathrm{MeOH}$ molecules have site occupancies of 0.5 and 0.72 per asymmetric unit (totalling $2.44 \mathrm{MeOH}$ molecules per complete cage).

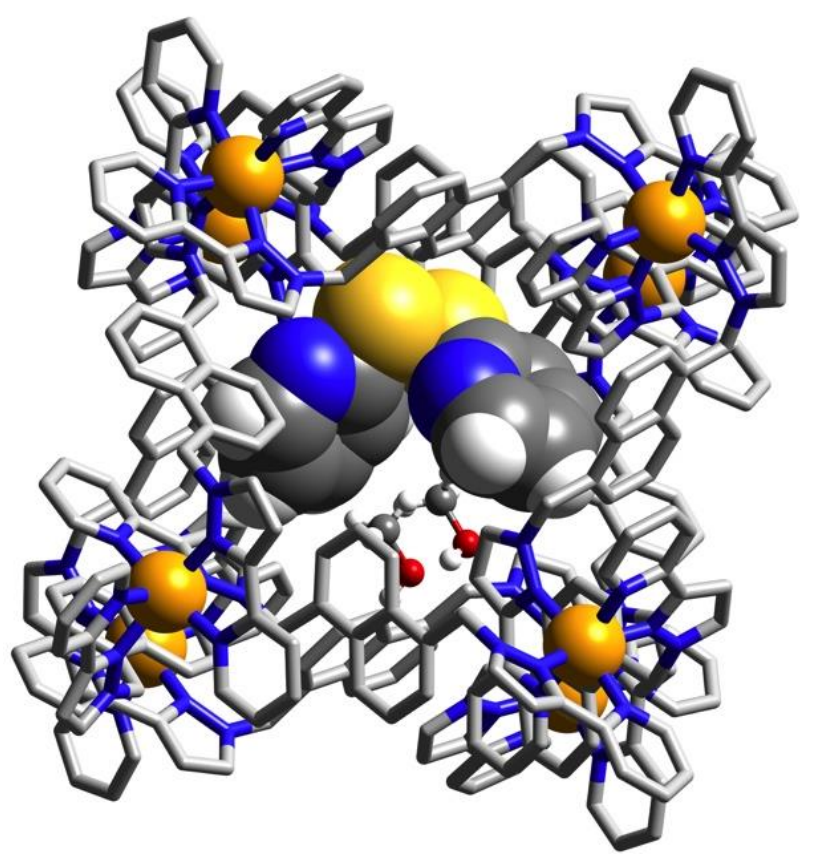

Figure 2. A view of the crystal structure of the complex of host $\mathbf{H}$ with guest $\mathrm{G}^{2 \mathrm{Py}}$ (and two molecules of $\mathrm{MeOH}$ ). The host cage is shown in wireframe and $\mathrm{G}^{2 \mathbf{P y}}$ is shown space-filling ( $\mathrm{N}$ atoms, blue; $\mathrm{O}$ atoms, red; Co atoms, orange; C atoms, grey).

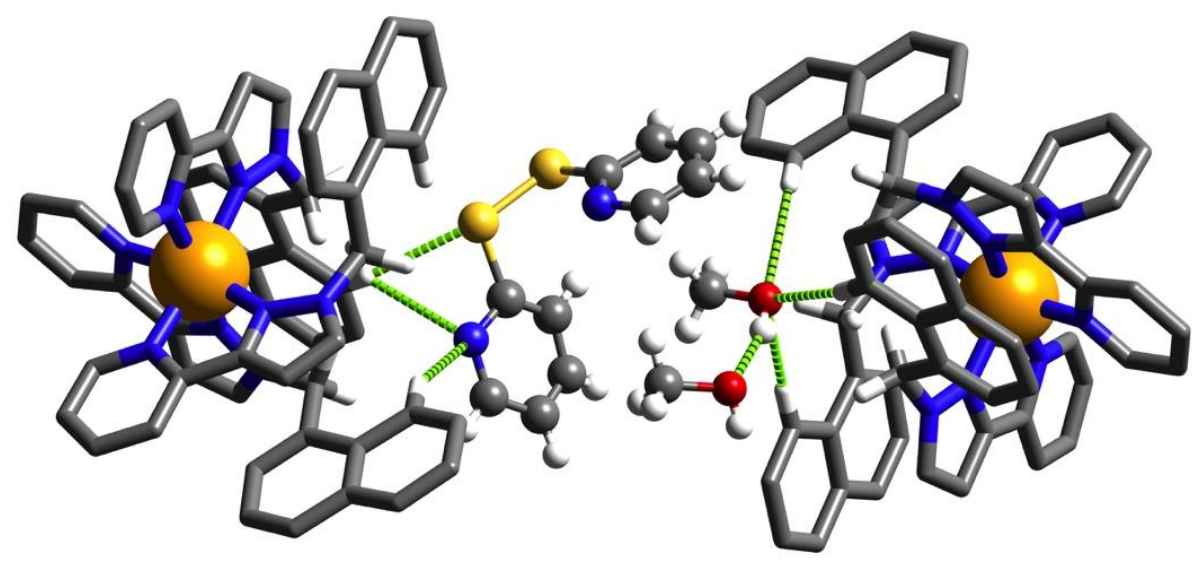

Figure 3. Partial view of the structure of the $\mathbf{H} / \mathrm{G}^{2 \mathbf{P y}}$ complex showing the network of $\mathrm{CH} \cdots \mathrm{O}$ contacts (shown by green dotted lines) between the $\mathrm{G}^{2 \mathrm{Py}}$ and $\mathrm{MeOH}$ guests with a convergent set of $\mathrm{CH}$ groups associated with the cage interior surface around the two fac tris-chelate metal complex vertices of $\mathbf{H}$.

The guest $\mathrm{G}^{2 \mathrm{Py}}$ has a molecular volume of $209 \AA^{2}$ and therefore occupies $51 \%$ of the cavity volume. The stoichiometry of $\mathbf{H} \cdot\left(\mathbf{G}^{2 \mathbf{P y}}\right)_{0.5}(\mathrm{MeOH})_{2.5}$ is a compositional average: if we assume that some of the cages may contain one $\mathrm{G}^{2 \mathrm{Py}}$ guest in one pocket, and two $\mathrm{MeOH}$ molecules in the other as the maximum possible occupancy, the total volume of combined guests is $291 \AA^{3}$, which would be $71 \%$ of the cavity volume. This is somewhat higher than the optimal range of $55 \% \pm 9 \%$ for the volume of a guest (or combination of guests) compared to the volume of a host cavity [48,49], but significantly less than what we observed when a cavity contained a stacked pair of aromatic guests in close proximity [27].

The second example of a cavity-bound guest comes from 3,4,5,6-tetrachloro-1,2-benzoquinone (BQ), whose binding in a luminescent but isostructural $\mathrm{M}_{8} \mathrm{~L}_{12}$ cubic cage was studied recently in the context 
of cage-to-guest photoinduced electron-transfer [39]. Figure 4 shows the structure of the complete cage/guest complex. The guest is disordered over two orientations, with a site occupancy of $0.25 \mathrm{in}$ each position, giving $50 \%$ occupancy of the guest in the cavity overall. There are multiple $\mathrm{CH} \cdots \mathrm{X}(\mathrm{X}=\mathrm{O}, \mathrm{Cl})$ contacts between the interior surface of the cage and the BQ guest including $\mathrm{O}(21 \mathrm{G}) \cdots(\mathrm{H} 53 \mathrm{~F}), 2.83 \AA$; $\mathrm{O}(22 \mathrm{G}) \cdots(\mathrm{H} 54 \mathrm{~F}), 2.93 \AA$; and several $\mathrm{CH} \cdots \mathrm{Cl}$ contacts of $<3 \AA$. In this case the disc-like shape and rigidity of the guest prevents any one electron-rich atom from protruding into the H-bond donor pockets on the cage interior surfaces, as happens with more flexible guests [47], but the range of interactions between the cage interior surface and electron-rich guest atoms is clear. Importantly, the maximum dimension of $6.35 \AA$ between atom centres on opposite sides of the guest, from $\mathrm{Cl}(23)$ to $\mathrm{Cl}(26)$, is small enough for the guest to fit without any difficulties; this distance may be compared to the separation of $7.71 \AA$ between a para-oriented pair of nitrile $\mathrm{N}$ atoms in 1,2,4,5-tetracyanobenzene which fits inside the cage $\mathbf{H}$ [40], spanning the long diagonal; and the separation of $7.73 \AA$ between the two most highly separated atoms of 4-methyl-7-amino-coumarin (amine proton, and carbonyl $\mathrm{O}$ atom) which-like many other coumarin derivatives—also fits inside the host cage $\mathbf{H}$ [37]. The molecular volume of $\mathbf{B Q}$ is $162 \AA^{3}$, so in this 1:1 cage-guest complex, the cavity occupancy is $40 \%$.
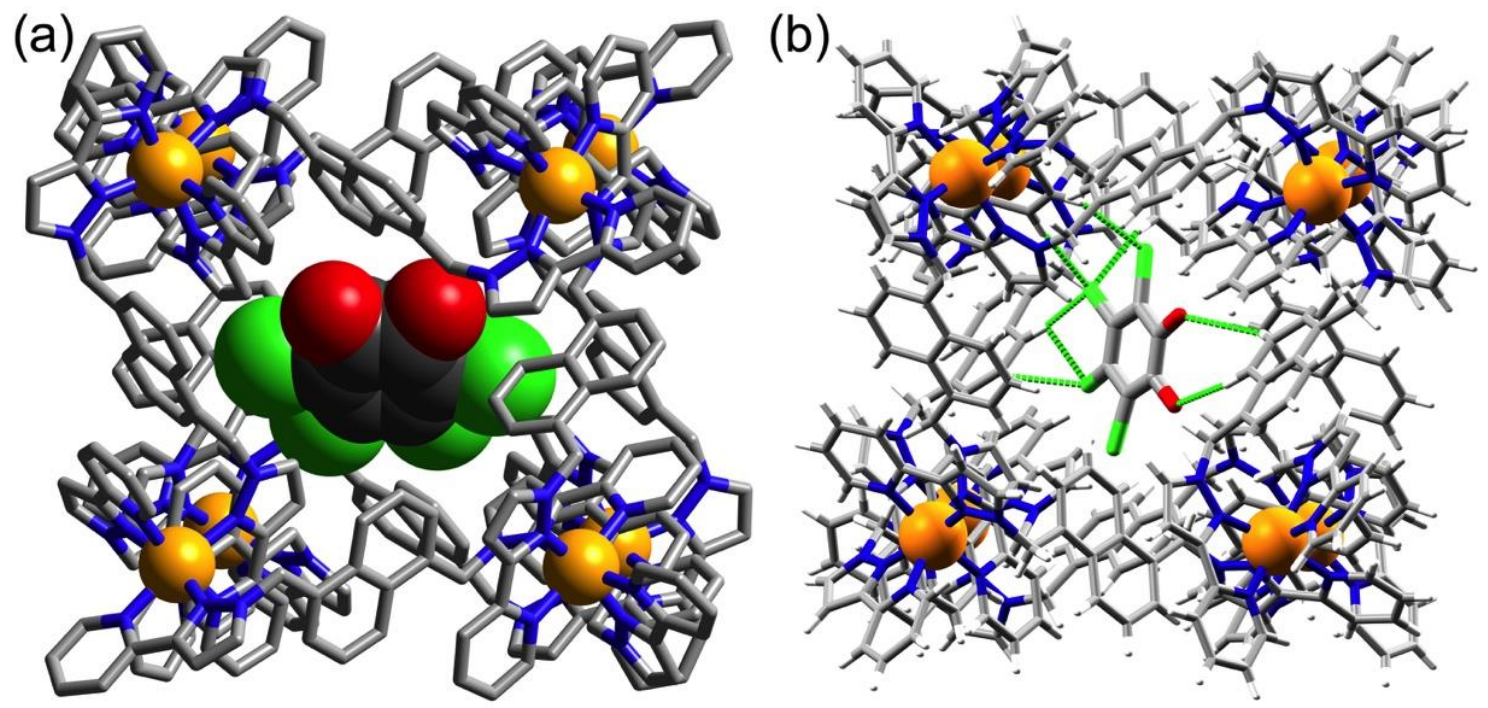

Figure 4. (a): A view of the crystal structure of the complex of host $\mathbf{H}$ with guest $\mathbf{B Q}$. The host cage is shown in wireframe and $\mathrm{G}^{2 \mathrm{Py}}$ is shown space-filling ( $\mathrm{N}$ atoms, blue; $\mathrm{O}$ atoms, red; Co atoms, orange; $\mathrm{C}$ atoms, grey; $\mathrm{Cl}$ atoms, green). (b): Alterative view of the complex emphasising the $\mathrm{CH} \cdots \mathrm{O}$ and $\mathrm{CH} \cdots \mathrm{Cl}$ interactions between cage and guest.

With 7-methoxycoumarin (MC), however, the additional size of the exocyclic substituent compared to 4-methyl-7-amino-coumarin $\left(\mathrm{a} \mathrm{CH}_{3} \mathrm{O}\right.$ substituent instead of an $\mathrm{NH}_{2}$ substituent at the coumarin $\mathrm{C}^{7}$ position) means that the molecule is now too long (ca. $9 \AA$ ) to fit inside the cage cavity even though, with a molecular volume of $176 \AA^{3}$, it is only $43 \%$ of the cage cavity volume. The crystalline sponge experiment using crystals of $\mathbf{H}$ soaked in a concentrated solution of $\mathbf{M C}$ showed that the $\mathbf{M C}$ molecules, one per cage, were taken up into the lattice in the spaces between cage molecules with no uptake of MC into the cage cavity (Figure 5). The MC molecules form partially overlapping stacked pairs with a separation of ca. $3.6 \AA$ between overlapping segments. Whereas one face of each MC is stacked with a symmetry-equivalent neighbour, the other face is in contact with the cages' exterior surface via a collection of $\mathrm{CH} \cdots \mathrm{O}$ hydrogen bonds. These contacts involve the coumarin ester $\mathrm{O}$ atoms which form hydrogen bonds with pyrazolyl $\mathrm{CH}$ protons from one cage complex $[\mathrm{O}(17 \mathrm{G}) \cdots \mathrm{H}(23 \mathrm{C})$, $2.46 \AA ; \mathrm{O}(16 \mathrm{G}) \cdots \mathrm{H}(44 \mathrm{~F}), 2.74 \AA$ ]; and the methoxy $\mathrm{O}$ atom which forms a pair of hydrogen bonds with two adjacent pyrazolyl $\mathrm{CH}$ protons from an adjacent cage exterior surface $[\mathrm{O}(25 \mathrm{G}) \cdots \mathrm{H}(44 \mathrm{D}), 2.77 \AA$; and $\mathrm{O}(25 \mathrm{G}) \cdots \mathrm{H}(43 \mathrm{D}), 2.78 \AA ̊ .7$. All three oxygen atoms of the MC molecule therefore participate in 
$\mathrm{CH} \cdots \mathrm{O}$ interactions with the exterior surface of cage molecules in just the same way as do guests that lie inside the cage cavity.

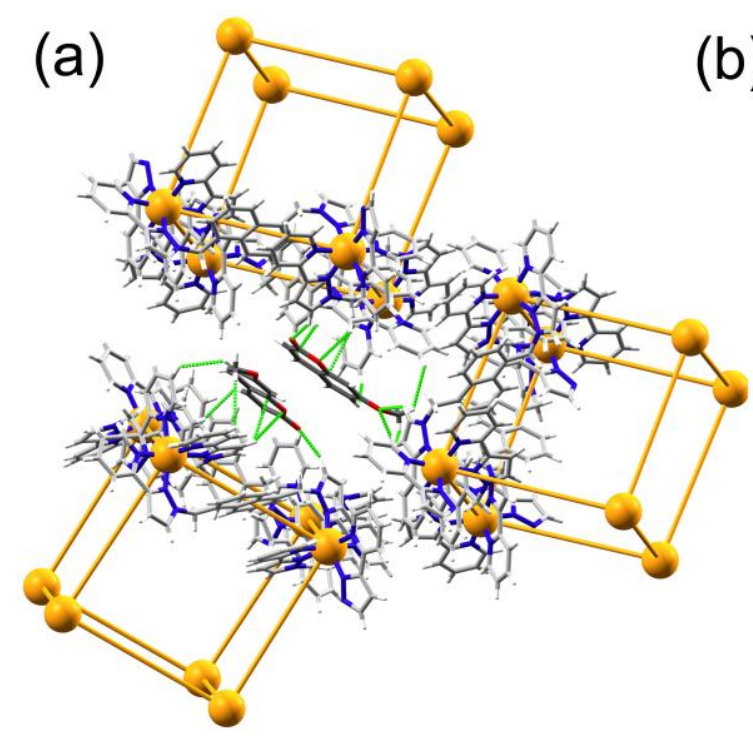

(b)

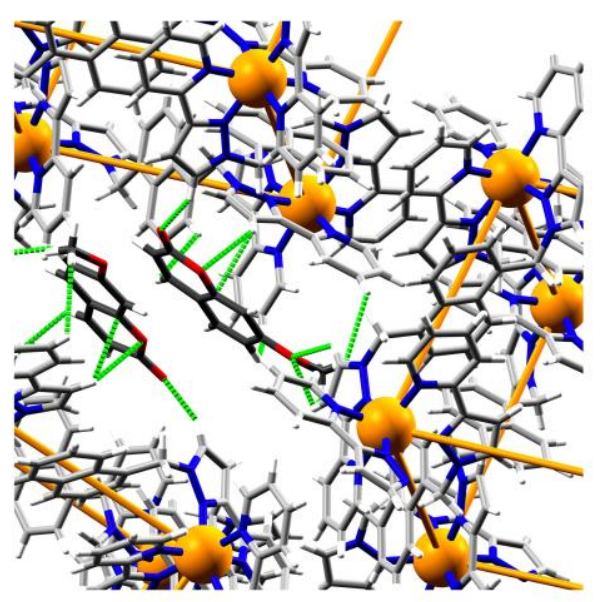

Figure 5. A view of the crystal structure of the complex of host $\mathbf{H}$ with guest $\mathbf{M C}$, showing how a stacked pair of guests in the space between molecules of $\mathbf{H}$ forms a range of $\mathrm{CH}$... O interactions with the cage exterior surfaces ( $\mathrm{N}$ atoms, blue; $\mathrm{O}$ atoms, red; Co atoms, orange; $\mathrm{C}$ atoms, grey). (a) A view showing the relationship of a stacked pair of MC molecules to three surrounding cage units; (b) a magnified view emphasising the interactions involving the MC units with exterior surfaces of nearby cage units.

Another feature of interest in this structure is that-since there was no uptake of the MC molecules into the cage cavity - the cavity of $\mathbf{H}$ is occupied with a network of hydrogen-bonded $\mathrm{MeOH}$ molecules. In other structures of cage $\mathbf{H}$, we could generally identify two solvent molecules in the cage cavity $(\mathrm{MeOH}$, water, dmf), one in each of the two H-bond donor pockets of the cage interior surface $[21,38,39]$. In one case when a pre-formed crystal of $\mathbf{H}$ had been soaked in water, we identified a cluster of ten hydrogen-bonded water molecules occupying the cavity, which provided interesting insights into the operation of the hydrophobic effect for guest binding in these cages [24]. In the structure of the $\mathbf{H} \cdot \mathbf{M C}$ adduct reported here, the use of synchrotron radiation and the resulting higher quality of the structure compared to those obtained with a standard laboratory diffractometer has allowed us to resolve a set of $\mathrm{MeOH}$ guest molecules in 4 positions in the asymmetric unit, which consists of half of a cage.

Two of these $\mathrm{MeOH}$ molecules are a closely-spaced disordered pair with a combined site occupancy of 1 per asymmetric unit; the other two have site occupancies of 0.75 . Overall, the site occupancies of $\mathrm{MeOH}$ molecules in the four unique positions in the asymmetric unit [0.75, 0.75, 0.65 and 0.35 for $\mathrm{O}(11 \mathrm{~S}), \mathrm{O}(12 \mathrm{~S}), \mathrm{O}(13 \mathrm{~S})$ and $\mathrm{O}(14 \mathrm{~S})$, respectively] mean that there are $2.5 \mathrm{MeOH}$ molecules per asymmetric unit, and the average occupancy of the complete cage cavity is therefore five $\mathrm{MeOH}$ molecules. However, this is a compositional average in the whole crystal and may reflect the fact that some cavities are fully occupied by six molecules with both $\mathrm{O}(11 \mathrm{~S})$ and $\mathrm{O}(12 \mathrm{~S})$ being present as well as the $\mathrm{O}(13 \mathrm{~S}) / \mathrm{O}(14 \mathrm{~S})$ disordered pair. We can see that the set of six $\mathrm{MeOH}$ molecules - when they are all present-forms a nicely hydrogen-bonded set (Figure 6) based on $\mathrm{OH} \cdots \mathrm{O}$ interactions between two pairs of $\mathrm{MeOH}$ molecules (signalled by $\mathrm{O} \cdots \mathrm{O}$ distances of $2.73 \AA$ ), and numerous $\mathrm{CH} \cdot \cdots \mathrm{O}$ interactions (signalled by C... O distances in the range 2.4-3 $\AA$ ), between $\mathrm{MeOH}$ molecules and also between two of the $\mathrm{MeOH}$ molecules and the $\mathrm{H}$-bond donor pockets of the cage surface (Figure $6 \mathrm{~b}$ ). A MeOH molecule has a volume of $40.7 \AA^{3}$, so the combined set $\left(244 \AA^{3}\right.$ ) occupies $60 \%$ of the cavity volume, within the optimal range of the Rebek occupancy rule [48,49]. 

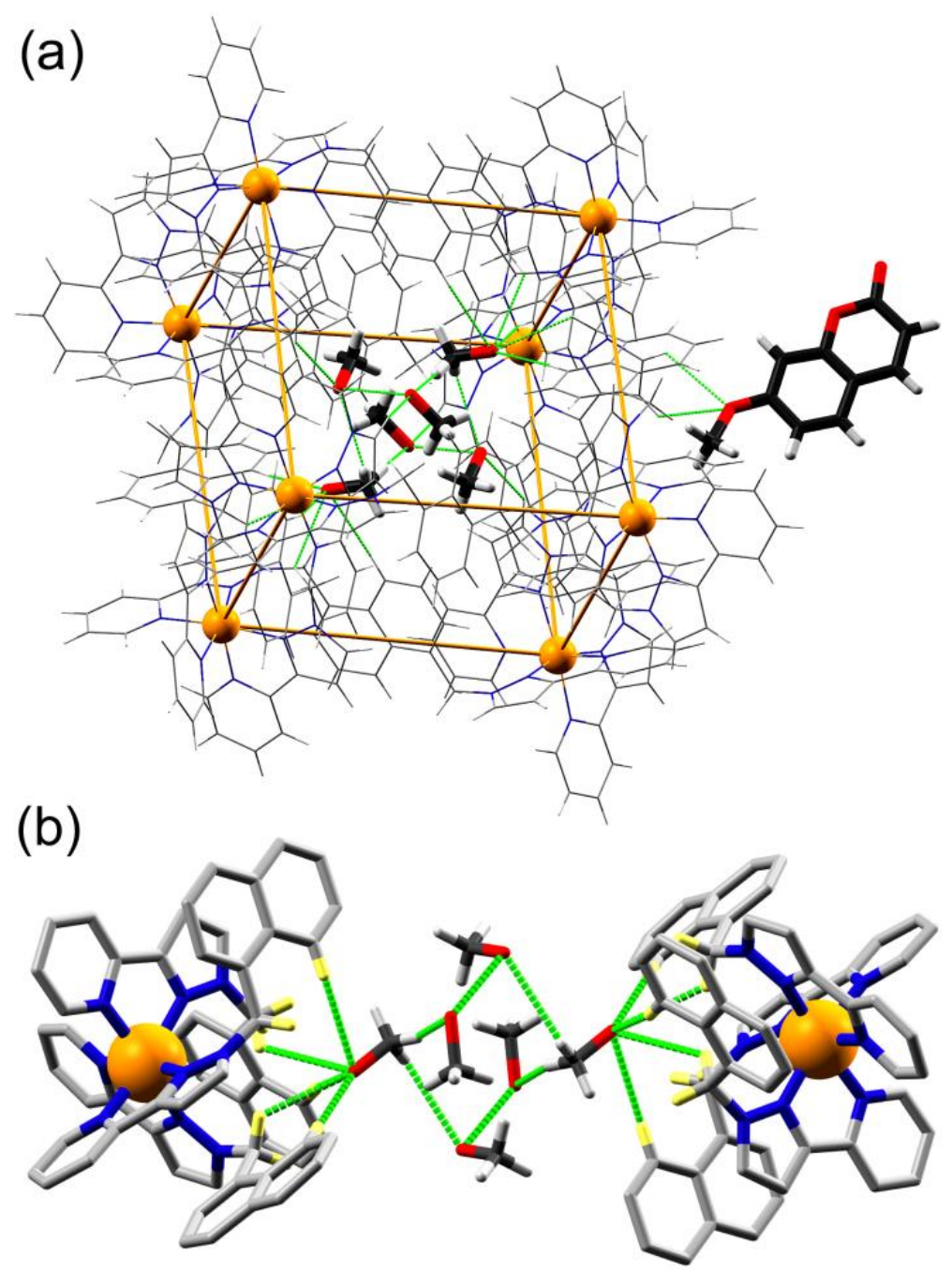

Figure 6. (a) A view of the cluster of six hydrogen-bonded $\mathrm{MeOH}$ molecules inside the cavity of $\mathbf{H}$ in the same crystal structure as shown in Figure 5, with one molecule of MC shown outside the cage ( $\mathrm{N}$ atoms, blue; $\mathrm{O}$ atoms, red; $\mathrm{Co}$ atoms, orange; $\mathrm{C}$ atoms, grey) and $\mathrm{CH} \cdots \mathrm{O} \mathrm{H}$-bonding interactions shown as green dotted lines. (b) An expanded view of the set of six $\mathrm{MeOH}$ molecules interacting with the two fac tris-chelate pockets on the cage interior surface.

Finally, in this section, we describe two structures containing acetophenone derivatives as guests-2-methylacetophenone (MA, volume $156 \AA^{3}$ ) and 2-methoxyacetophenone (MOA, volume $165 \AA^{3}$ )—in which guests are present in the crystals at both types of site, i.e., within the host cavity and outside the host cavity. In both cases, these guests are small enough, and of the appropriate shape, for a $\pi$-stacked pair of guests, lying across an inversion centre, to lie inside the cavity with the carbonyl $\mathrm{O}$ atoms docked into the two H-bond donor pockets on the cage interior surface located at the convergent set of $\mathrm{CH}$ protons around the $\mathrm{fac}$ tris-chelate metal vertices. This arrangement is similar to what we recently observed with a variety of other substituted aromatic guests containing H-bond acceptor substituents that occupied the cavity of $\mathbf{H}$ in stacked pairs. Interestingly, the guest $\mathbf{B} \mathbf{Q}$, which has a very similar volume to these two, did not form stacked pairs in the cage cavity, presumably because its disc-like shape means that a stacked pair is not ideally matched to the slightly elongated shape of the cavity of $\mathbf{H}$-which does, however, accommodate pairs of the more elongated molecules MA and MOA.

With guest MA, the site occupancy at each of the two equivalent sites inside $\mathbf{H}$ is 0.64 , i.e., $1.28 \mathrm{MA}$ guests inside each cavity on average (Figure 7a). The shortest $\mathrm{CH}$... O contacts that these form to the 
cage interior surface are $\mathrm{O}(22 \mathrm{G}) \cdots \mathrm{H}(61 \mathrm{D}), 2.49 \AA$; and $\mathrm{O}(22 \mathrm{G}) \cdots \mathrm{H}(54 \mathrm{C}), 2.64 \AA$ (shown in Figure 8 a as dotted lines). This pair of guests occupies $76 \%$ of the cavity volume. This is considerably higher than usually found in cage/guest complexes but is facilitated by the close association of the guest pair by $\pi$-stacking as well as hydrogen-bonding interactions between the guests and the cage interior surface, both of which facilitate a high guest packing density [37,50]. In addition, MA molecules occupy spaces in the lattice outside the cages, one with unit occupancy (but disordered over two closely-spaced sites) and the other with 0.59 occupancy (shared with 0.41 of a $\mathrm{MeOH}$ molecule at the same position). As in the structure with guest $\mathrm{MC}$, we see short $\mathrm{CH} \cdots \mathrm{O}$ contacts between the carbonyl $\mathrm{O}$ atom and externally-directed $\mathrm{CH}$ groups on the cage surface with $\mathrm{H} \cdots \mathrm{O}$ separations in the range $2.67-2.97 \AA$.
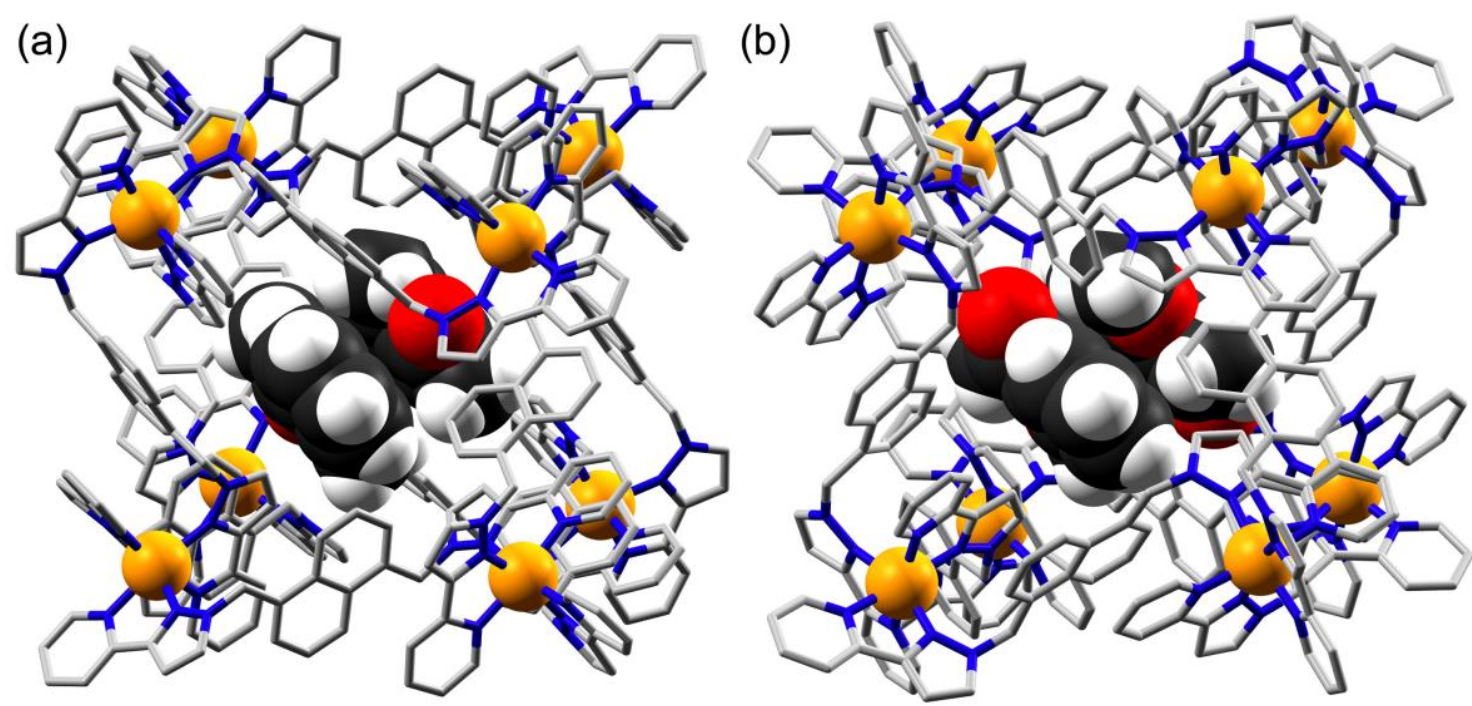

Figure 7. Views of the crystal structures of the complexes of host $\mathbf{H}$ (in wireframe) with a stacked pair of (a) guests MA and (b) guests MOA (guests shown space-filling: $\mathrm{N}$ atoms, blue; $\mathrm{O}$ atoms, red; Co atoms, orange; C atoms, grey).

The guest MOA behaves very similarly with a stacked pair of guests inside the cavity (see Figure 7b; occupancy of 0.97 in each of the two equivalent positions) and one guest outside the cage with a site occupancy of 0.78 . The interior guests form $\mathrm{CH} \cdots \mathrm{O}$ hydrogen-bond interactions between the carbonyl $\mathrm{O}$ atom $\mathrm{O}(23 \mathrm{G})$ and $\mathrm{CH}$ protons around the cage interior $\mathrm{H}$-bond donor pockets, with the shortest of these being $\mathrm{O}(23 \mathrm{G}) \cdots \mathrm{H}(54 \mathrm{~F}), 2.48 \AA$; and $\mathrm{O}(23 \mathrm{G}) \cdots \mathrm{H}(54 \mathrm{C}), 2.53 \AA$ (Figure $8 \mathrm{~b})$. The pair of guests gives a remarkably high cavity occupancy of $80 \%$, which is still, however, some way short of the maximum we have seen of $87 \%$ [37]. The exterior guest is oriented such that it forms similarly short contacts to the cage exterior surface with $\mathrm{O}(23 \mathrm{H}) \cdots \mathrm{H}$ separations as short as $2.41 \AA$ (to H13E) and $2.52 \AA$ (to H24E).

Overall, this set of structures illustrates the point that was made in the introduction, which is that, whilst cage/guest interactions to the interior surface are involved in internal guest binding, cage/guest interactions can also occur to the exterior surface of host $\mathbf{H}$. In the crystal structures, the most obvious weak interactions are, of course, directional hydrogen-bonding interactions, whereas, in aqueous solution, these will be insignificant because of solvation effects and it is the hydrophobic contacts between host and guest surfaces responsible for binding [21,22], but the same principle can apply -as we have already demonstrated in recent work on reactions between hydrophobic substrates and anions catalysed at the cage exterior surface [35]. In the next section, we show how one specific family of guests can form two distinct types of interaction with other cubic host cages isostructural to $\mathbf{H}$, as shown by luminescence studies, and we propose that these relate to interactions of the guests with interior and exterior surfaces which have different photophysical consequences. 

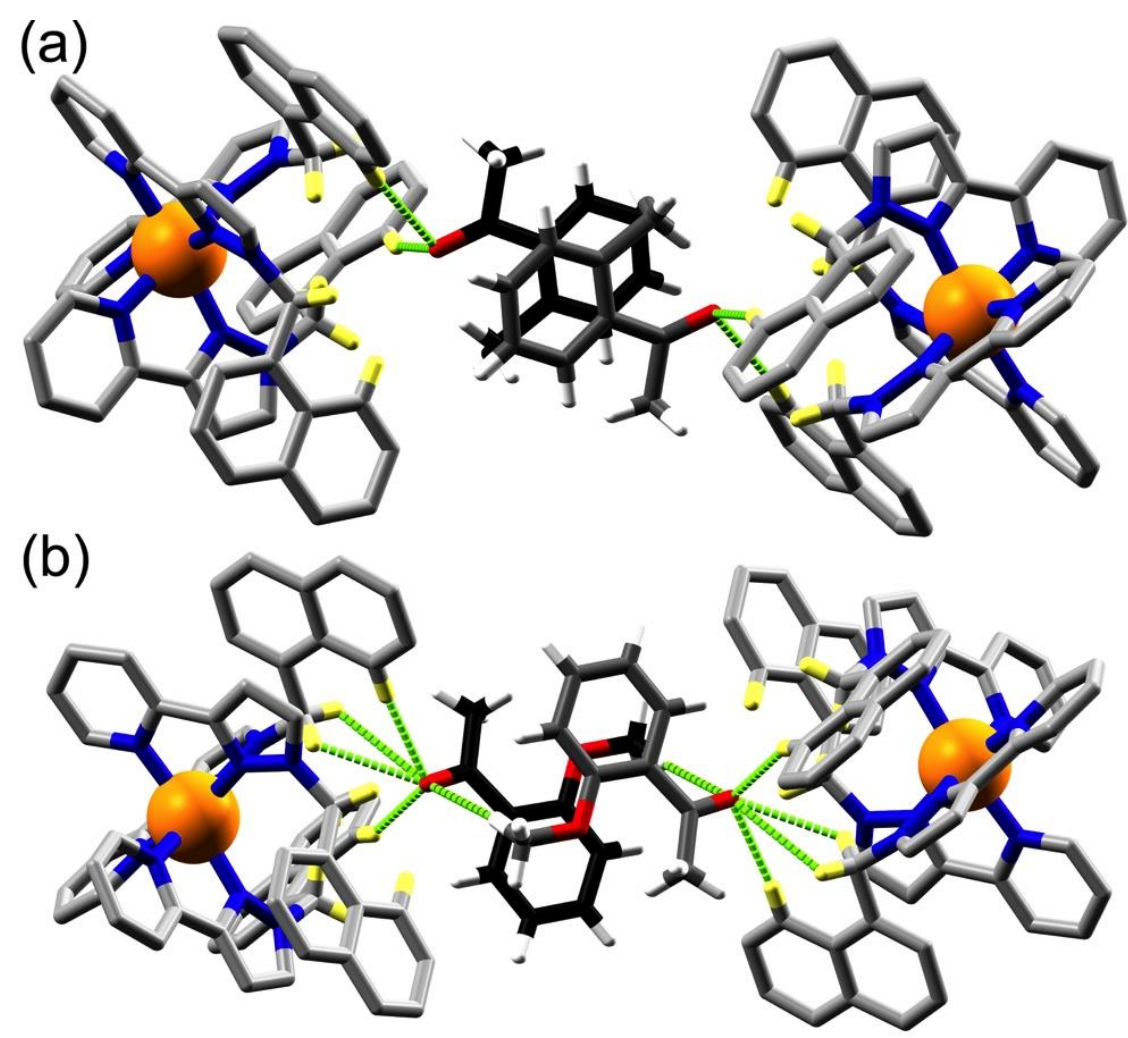

Figure 8. Partial views of the structures of (a) the $\mathbf{H} \cdot \mathbf{M A}$ complex and (b) the $\mathbf{H} \cdot \mathbf{M O A}$ complex showing the network of $\mathrm{CH}$... O contacts (shown by green dotted lines) between the two crystallographically equivalent guests, and the convergent set of $\mathrm{CH}$ groups associated with the cage interior surface around the two fac tris-chelate metal complex vertices of $\mathbf{H}$.

\subsection{Cage/Guest Interactions in Solution Studied by Fluorescence Titrations}

For the crystalline sponge studies reported above, we used $\left[\mathrm{Co}_{8} \mathrm{~L}_{12}\right]\left(\mathrm{BF}_{4}\right)_{16}(\mathbf{H})$ exclusively, as this forms robust crystals which retain their crystallinity after prolonged soaking in concentrated guest solution. However, as the fluoroborate salt, this is completely insoluble in aqueous solution, so for the solution studies in this section, we converted this cage to its water-soluble chloride salt. In this section, therefore, $\mathbf{H}^{\mathrm{Co}}$ denotes the octanuclear $\mathrm{Co}(\mathrm{II})$ species $\left[\mathrm{Co}_{8} \mathrm{~L}_{12}\right] \mathrm{Cl}_{16}$ in its water-solubilised form [31]. In addition, we employed a luminescent variant of this basic cage structure to allow use of luminescence titrations to probe cage/guest interactions. This is the fluorescent $\mathrm{Cd}_{8}$ cage $\left[\mathrm{Cd}_{8}\left(\mathrm{~L}^{\mathrm{W}}\right)_{12}\right]\left(\mathrm{NO}_{3}\right)_{16}$ in which water-solubility is promoted by the hydroxymethyl groups attached to the pyridyl rings at the $\mathrm{C}^{4}$ position (see Figure 1); we denote this as $\mathbf{H}^{\mathrm{Cd}}$ [39]. The interior cavity is structurally identical between $\mathbf{H}^{\mathrm{Co}}$ and $\mathbf{H}^{\mathrm{Cd}}$.

As guests for this solution study, we used some aromatic disulfides, including $\mathrm{G}^{2 \mathbf{P y}}$, which was also used for the structural studies described above, and $\mathrm{G}^{\mathrm{Cl}}$ [bis-(4-chlorophenyl)disulfide]. Binding of these guests in the cage cavity was established initially by ${ }^{1} \mathrm{H}$ NMR titrations using host $\mathbf{H}^{\text {Co }}$. The paramagnetism associated with the high-spin $\mathrm{Co}(\mathrm{II})$ ions disperses the ${ }^{1} \mathrm{H}$ NMR signals over the range ca. -100 to $+100 \mathrm{ppm}$, making gradual shifts of individual signals as a guest binds during a titration particularly easy to see [21-24,35-38]. The resulting plots of $\Delta \delta$ as a function of added guest could—as usual—be fit to a 1:1 binding model, yielding binding constants of $2.5 \times 10^{3} \mathrm{M}^{-1}$ for $\mathrm{G}^{2 \mathrm{Py}}$ and $5.0 \times 10^{4} \mathrm{M}^{-1}$ for $\mathrm{G}^{\mathrm{Cl}}$ inside host $\mathbf{H}^{\mathrm{Co}}$. The weaker binding of $\mathrm{G}^{2 \mathrm{Py}}$ compared to $\mathrm{G}^{\mathrm{Cl}}$ is consistent with the pyridyl groups providing greater water solubility for $\mathbf{G}^{2 \mathbf{P y}}$, i.e., it is less hydrophobic than $\mathrm{G}^{\mathrm{Cl}}$ and hydrophobicity is a major contribution to guest binding in water [24]. 
We next investigated the effect of binding these disulfides on the luminescence of $\mathbf{H}^{\mathrm{Cd}}$ by titrations of the cage with these disulfides in aqueous solution. Given that $\mathbf{H}^{\mathrm{Cd}}$ has a naphthyl $\pi-\pi^{*}$ excited state which is a good excited-state electron donor [39], and the disulfides are electron-acceptors via the existence of RSSR/(RSSR)- couples [51], we would expect to see varying degrees of quenching of the host luminescence on guest binding depending on the excited-state redox potential of the host and the redox potential of the disulfide guest.

In all cases, unexpectedly, we observed clear two-step behaviour with an initial increase in luminescence intensity during the early stages of the titration as small amounts of guest were added, quickly followed by the expected progressive quenching. Examples are shown in Figures 9 and 10. In the first case, on titration of the $\mathbf{H}^{\mathrm{Cd}}$ cage with $\mathbf{G}^{\mathbf{2 P y}}$, an initial increase in fluorescence intensity of ca. $20 \%$ in the early stages of the titration (up to addition of ca. 1 equivalent of guest) is then followed by a $>50 \%$ reduction in fluorescence intensity as more guest is added (Figure 9). Very similar behaviour is shown by titration of $\mathbf{H}^{\mathrm{Cd}}$ with $\mathbf{G}^{\mathrm{Cl}}$, with an initial increase in luminescence intensity of $20 \%$ followed by a decrease thereafter as the titration progresses (Figure 10). Solubility limitations of $\mathrm{G}^{\mathrm{Cl}}$ prevent this from going to completion, but it is clear that the quenching of fluorescence intensity from the maximum is $>40 \%$ by the time the solubility limit of $\mathrm{G}^{\mathrm{Cl}}$ was reached.
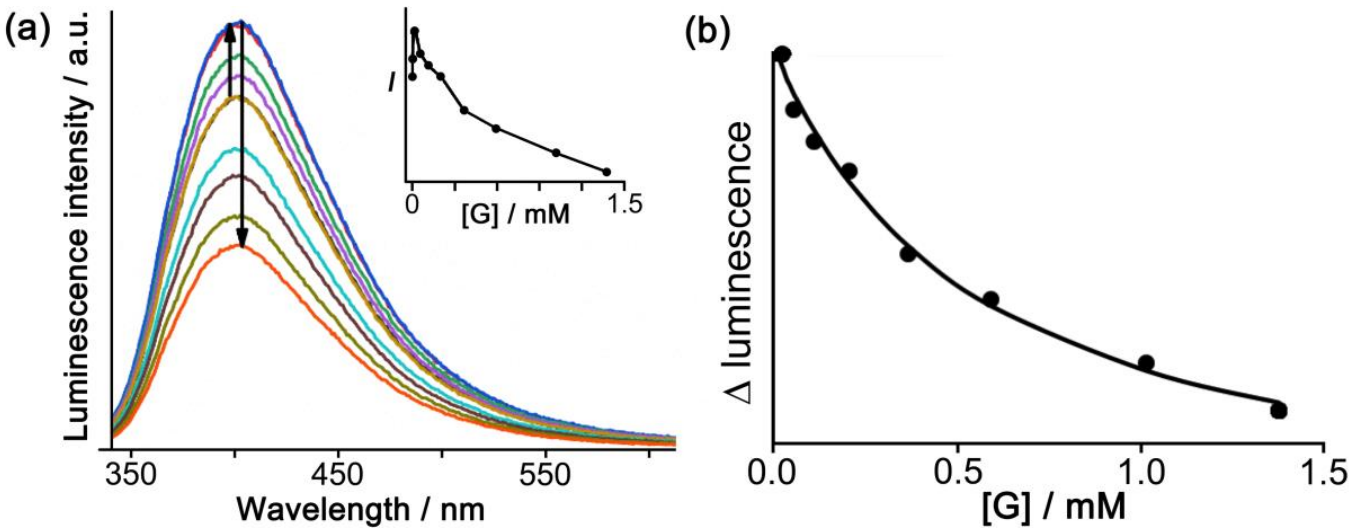

Figure 9. Change in intensity of luminescence from a solution of $\mathbf{H}^{\mathrm{Cd}}$ in water $(10 \mu \mathrm{M})$ during titration with bis(2-pyridyl)disulfide $\left(\mathrm{G}^{2 \mathbf{P y}}\right)$. (a) Sequence of fluorescence spectra showing the rise and then decay of fluorescence (indicated by the black arrows) as portions of $\mathbf{G}^{2 \mathbf{P y}}$ are added during the titration, with (inset) changes to peak intensity; (b) fitting of the luminescence decay during the second part of the titration to a 1:1 binding isotherm.

We have never seen this two-step change, i.e., an early-stage increase and then a slower decrease in luminescence, in any of our other recent work on measuring guest binding in cages of the $\mathbf{H}$ family using luminescence titrations $[39,40,52]$. It is not simply associated with very slow uptake of guest by the cage as each individual measurement did not change with time, and indeed, during the NMR titration of guest binding, we observed that guest exchange is fast on the NMR timescale with a single set of signals being observed for the cage at an weighted average position for the 'free' and 'bound' cage at each point during the titration. This new two-stage behaviour implies the presence of two different types of cage/guest interaction with different equilibrium constants and opposite effects: a stronger interaction leading to the increase in luminescence early in the titration as the first equivalent of guest is added, and a weaker interaction which dominates the later stages of the titration as more guest is added, and which leads to the quenching.

Given that guest binding inside the cavities of these cages is expected to provide efficient quenching because of the proximity of the guest to all members of the chromophore array [39,40], we suggest that the second (quenching) component is associated with the disulfide guest binding inside the cage cavity in the manner shown by the crystal structure above. Additional evidence for this comes from the observation that fitting this later part of the spectroscopic titration-the intensity decrease phase, 
starting from the maximum attained after 1 equivalent of guest- to a 1:1 binding model gives binding constants comparable to those obtained from the NMR titrations. For example, the luminescence quenching in Figure $9 \mathrm{~b}$ could be fitted to a binding constant of $2.0 \times 10^{3} \mathrm{M}^{-1}$ for the host/guest complex with $\mathrm{G}^{2 \mathrm{Py}}$ ( $c f .2 .5 \times 10^{3} \mathrm{M}^{-1}$ by ${ }^{1} \mathrm{H}$ NMR using the $\mathrm{Co}_{8}$ cage $\mathbf{H}^{\mathrm{Co}}$ ), and with the $\mathbf{H}^{\mathrm{Cd}} / \mathrm{G}^{\mathrm{Cl}}$ titration, this intensity decay phase afforded a binding constant of $2 \times 10^{5} \mathrm{M}^{-1}$. This is somewhat larger than the value of $5 \times 10^{4} \mathrm{M}^{-1}$ obtained from the NMR titration of the $\mathrm{H}^{\mathrm{Co}} / \mathrm{G}^{\mathrm{Cl}}$ pair, but we note that $\mathrm{H}^{\mathrm{Co}}$ and $\mathbf{H}^{\mathrm{Cd}}$ have different counter-ions (chloride vs. nitrate), which affects guest binding constants slightly [31,39]. Fitting the initial phase of the titration (increase in intensity) to a 1:1 binding model was more difficult, as there were few data points from this early stage and the change was basically linear up to addition of the first equivalent of guest, implying an equilibrium constant of $>>10^{5} \mathrm{M}^{-1}$ for this first interaction (given the concentration of $\mathbf{H}^{\mathrm{Cd}}$ of $10 \mu \mathrm{M}$ ).
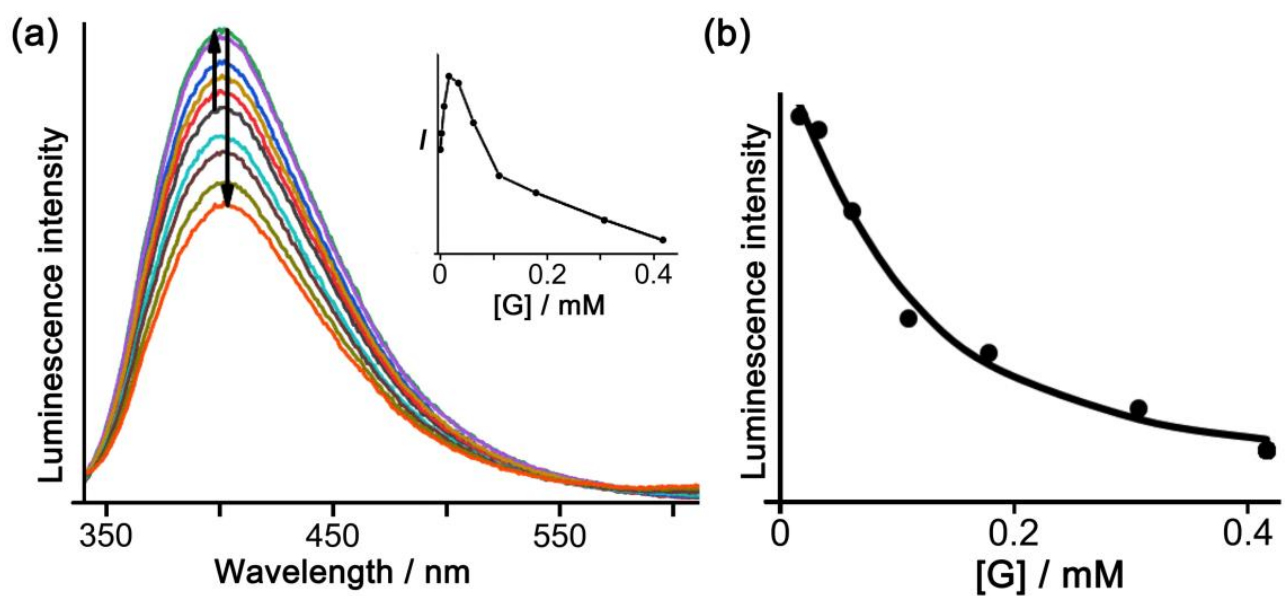

Figure 10. Change in intensity of luminescence from a solution of $\mathbf{H}^{\mathrm{Cd}}$ in water $(10 \mu \mathrm{M})$ during titration with bis(4-chlorophenyl)disulfide $\left(\mathrm{G}^{\mathrm{Cl}}\right)$. (a) Sequence of fluorescence spectra showing the rise and then decay of fluorescence (indicated by the black arrows) as portions of $\mathrm{G}^{\mathrm{Cl}}$ are added during the titration, with (inset) changes to peak intensity; (b) fitting of the luminescence decay during the second part of the titration to a 1:1 binding isotherm.

We suggest that the initial strong interaction is association of the guest with the exterior surface of the cage driven predominantly by the hydrophobic effect, in the same way that any hydrophobic species tends to aggregate in water. The small increase in luminescence could be explained by an increase in rigidity of the cage for which the majority of the excited states are quenched by non-radiative pathways including molecular vibrations. We have shown before that rigidification of a luminescent cage assembly using a non-chromophoric guest can lead to a modest increase in luminescence intensity [39], and this may compensate for any quenching effects associated with this exterior binding, given that a surface-bound guest will be remote from many of the naphthyl chromophores in the cage and, therefore, not quench them effectively compared to a cavity-bound guest. As guest concentration increases and the cavity starts to become significantly occupied, the quenching behaviour dominates in the later stages of the titrations because the cavity-bound guests are optimally positioned-as close to all of the chromophores in the cage as possible-for the maximum possible quenching effect. The fact that no cage/guest system shows complete quenching is ascribable to the equilibrium between cage/guest complexes and free cage: the limited solubility in water of these hydrophobic and, therefore, poorly water-soluble disulfides prevents the equilibria from being driven near to completion using a large excess of guest. Thus, there is always free (unquenched) cage present. 


\section{Discussion}

Why the two-stage binding behaviour should occur with aromatic disulfides but not with any of the other guests whose binding has previously been examined using luminescence methods [39,40,52] is unclear. We note, however, that all of our previous examples of guest binding examined by luminescence methods have used relatively rigid or compact guests, whereas these disulfides have a more extended shape and greater conformational flexibility associated with torsions around C-S and S-S bonds. On this basis, we propose that, in addition to the cavity-binding of the guest as observed in the $\mathbf{H} / \mathbf{G}^{2 \mathbf{P y}}$ crystal structure, there also exists a favourable geometry for these guests to interact with the exterior surface in solution as we have seen in a few other crystal structures with different guests [35-38].

Overall, the combination of structural studies of host $\mathbf{H}$ with a range of small-molecule guests, and the unexpected two-stage luminescence behaviour observed in solution, are consistent with the simple principle that the exterior surfaces of cage hosts provide means for interacting with guests just as much as the interior surfaces do, as has been pointed out by Nitschke [32] and Raymond [33]. This emphasises recent results that we obtained using cages as catalysts for reactions with anions, with hydrophobic association of cage/substrate occurring even when cavity binding was not possible [35]. Synthetic capsule or cage-type hosts remain fascinating targets for study for many reasons and whilst their tailored internal spaces have a major role to play in their functional behaviour, the external surfaces are clearly also significant.

Supplementary Materials: The following are available online at http://www.mdpi.com/2624-8549/2/2/31/s1: crystallographic CIF and CIF-check files.

Author Contributions: Crystalline sponge experiments and X-ray crystallography: C.G.P.T.; fluorescence titrations: J.S.T.; and project conception, supervision and manuscript preparation: M.D.W. All authors have read and agreed to the published version of the manuscript.

Funding: This research received no external funding.

Acknowledgments: We thank the Diamond Light Source for the X-ray beamtime (proposal MT19876) and the staff of beamline I-19 for their assistance. Jerico Piper is thanked for providing a sample of $\mathbf{H}^{\mathrm{Cd}}$. Miss Cristina Mozaceanu, Jerico Piper and Stephen Argent (University of Warwick), and Sarah Barnett (Diamond Light Source), are thanked for assistance with some of the X-ray data collections.

Conflicts of Interest: The authors declare no conflict of interest.

\section{References}

1. Zhang, D.; Ronson, T.K.; Nitschke, J.R. Functional Capsules via Subcomponent Self-Assembly. Acc. Chem. Res. 2018, 51, 2423-2436. [CrossRef] [PubMed]

2. Yoshizawa, M.; Klosterman, J.K.; Fujita, M. Functional molecular flasks: New properties and reactions within discrete, self-assembled hosts. Angew. Chem. Int. Ed. 2009, 48, 3418-3438. [CrossRef] [PubMed]

3. Vardhan, H.; Yusubov, M.S.; Verpoort, F. Self-assembled metal-organic polyhedra: An overview of various applications. Coord. Chem. Rev. 2016, 306, 171-194. [CrossRef]

4. Cook, T.R.; Stang, P. Recent Developments in the preparation and chemistry of metallacycles and metallacages via coordination. Chem. Rev. 2015, 115, 7001-7045. [CrossRef] [PubMed]

5. Chakrabarty, R.; Mukherjee, P.S.; Stang, P. Supramolecular Coordination: Self-Assembly of Finite Two- and Three-Dimensional Ensembles. Chem. Rev. 2011, 111, 6810-6918. [CrossRef]

6. Otte, M. Size-Selective Molecular Flasks. ACS Catal. 2016, 6, 6491-6510. [CrossRef]

7. Jing, X.; He, C.; Zhao, L.; Duan, C. Photochemical Properties of Host-Guest Supramolecular Systems with Structurally Confined Metal-Organic Capsules. Acc. Chem. Res. 2018, 52, 100-109. [CrossRef]

8. Catti, L.; Zhang, Q.; Tiefenbacher, K. Advantages of catalysis in self-assembled molecular capsules. Chem. Eur. J. 2016, 22, 9060-9066. [CrossRef]

9. Brown, C.J.; Toste, F.D.; Bergman, R.G.; Raymond, K.N. Supramolecular Catalysis in Metal-Ligand Cluster Hosts. Chem. Rev. 2015, 115, 3012-3035. [CrossRef] 
10. Fang, Y.; Powell, J.A.; Li, E.; Wang, Q.; Perry, Z.; Kirchon, A.; Yang, X.; Xiao, Z.; Zhu, C.; Zhang, L.; et al. Catalytic reactions within the cavity of coordination cages. Chem. Soc. Rev. 2019, 48, 4707-4730. [CrossRef]

11. Gao, W.-X.; Zhang, H.-N.; Jin, G.-X. Supramolecular catalysis based on discrete heterometallic coordination-driven metallacycles and metallacages. Coord. Chem. Rev. 2019, 386, 69-84. [CrossRef]

12. Hong, C.M.; Bergman, R.G.; Raymond, K.N.; Toste, F.D. Self-Assembled Tetrahedral Hosts as Supramolecular Catalysts. Acc. Chem. Res. 2018, 51, 2447-2455. [CrossRef] [PubMed]

13. Grommet, A.B.; Nitschke, J.R. Directed Phase Transfer of an FeII4L4 Cage and Encapsulated Cargo. J. Am. Chem. Soc. 2017, 139, 2176-2179. [CrossRef] [PubMed]

14. Garci, A.; Mbakidi, J.-P.; Chaleix, V.; Sol, V.; Orhan, E.; Therrien, B. Tunable Arene Ruthenium Metallaprisms to Transport, Shield, and Release Porphin in Cancer Cells. Organometallics 2015, 34, 4138-4146. [CrossRef]

15. Mihara, N.; Ronson, T.K.; Nitschke, J.R. Different Modes of Anion Response Cause Circulatory Phase Transfer of a Coordination Cage with Controlled Directionality. Angew. Chem. Int. Ed. 2019, 58, 12497-12501. [CrossRef]

16. Grancha, T.; Carne-Sanchez, A.; Hernández-López, L.; Albalad, J.; Imaz, I.; Juanhuix, J.; Maspoch, D. Phase Transfer of Rhodium(II)-Based Metal-Organic Polyhedra Bearing Coordinatively Bound Cargo Enables Molecular Separation. J. Am. Chem. Soc. 2019, 141, 18349-18355. [CrossRef]

17. Saha, M.L.; Yan, X.; Stang, P. Photophysical Properties of Organoplatinum(II) Compounds and Derived Self-Assembled Metallacycles and Metallacages: Fluorescence and its Applications. Acc. Chem. Res. 2016, 49, 2527-2539. [CrossRef]

18. Zhang, J.; Xie, S.; Zi, M.; Yuan, L. Recent advances of application of porous molecular cages for enantioselective recognition and separation. J. Sep. Sci. 2019, 43, 134-149. [CrossRef]

19. Martí-Centelles, V.; Lawrence, A.L.; Lusby, P.J. High Activity and Efficient Turnover by a Simple, Self-Assembled "Artificial Diels-Alderase". J. Am. Chem. Soc. 2018, 140, 2862-2868. [CrossRef]

20. Custelcean, R.; Bonnesen, P.V.; Duncan, N.C.; Zhang, X.; Watson, L.A.; Van Berkel, G.; Parson, W.B.; Hay, B.P. Urea-Functionalized M4L6 Cage Receptors: Anion-Templated Self-Assembly and Selective Guest Exchange in Aqueous Solutions. J. Am. Chem. Soc. 2012, 134, 8525-8534. [CrossRef]

21. Whitehead, M.; Turega, S.; Stephenson, A.; Hunter, C.A.; Ward, M.D. Quantification of solvent effects on molecular recognition in polyhedral coordination cage hosts. Chem. Sci. 2013, 4, 2744. [CrossRef]

22. Turega, S.; Cullen, W.; Whitehead, M.; Hunter, C.A.; Ward, M.D. Mapping the Internal Recognition Surface of an Octanuclear Coordination Cage Using Guest Libraries. J. Am. Chem. Soc. 2014, 136, 8475-8483. [CrossRef] [PubMed]

23. Cullen, W.; Turega, S.; Hunter, C.A.; Ward, M.D. Virtual screening for high affinity guests for synthetic supramolecular receptors. Chem. Sci. 2015, 6, 2790-2794. [CrossRef] [PubMed]

24. Metherell, A.; Cullen, W.; Williams, N.H.; Ward, M.D. Binding of Hydrophobic Guests in a Coordination Cage Cavity is Driven by Liberation of "High-Energy" Water. Chem. Eur. J. 2017, 24, 1554-1560. [CrossRef] [PubMed]

25. Leenders, S.H.A.M.; Becker, R.; Kumpulainen, T.; De Bruin, B.; Sawada, T.; Kato, T.; Fujita, M.; Reek, J.N.H. Selective Co-Encapsulation Inside an M6L4 Cage. Chem. Eur. J. 2016, 22, 15468-15474. [CrossRef] [PubMed]

26. Takezawa, H.; Murase, T.; Resnati, G.; Metrangolo, P.; Fujita, M. Halogen-bond-assisted guest inclusion in a synthetic cavity. Angew. Chem. Int. Ed. 2015, 54, 8411-8414. [CrossRef] [PubMed]

27. Rizzuto, F.J.; Von Krbek, L.; Nitschke, J.R. Strategies for binding multiple guests in metal-organic cages. Nat. Rev. Chem. 2019, 3, 204-222. [CrossRef]

28. Ibukuro, F.; Kusukawa, T.; Fujita, M. A Thermally Switchable Molecular Lock. Guest-Templated Synthesis of a Kinetically Stable Nanosized Cage. J. Am. Chem. Soc. 1998, 120, 8561-8562. [CrossRef]

29. Johnson, D.W.; Raymond, K.N. The role of guest molecules in the self-assembly of metal-ligand clusters. Supramol. Chem. 2001, 13, 639-659. [CrossRef]

30. Ward, M.D.; Hunter, C.A.; Williams, N.H. Coordination Cages Based on Bis(pyrazolylpyridine) Ligands: Structures, Dynamic Behavior, Guest Binding, and Catalysis. Acc. Chem. Res. 2018, 51, 2073-2082. [CrossRef]

31. Cullen, W.; Metherell, A.J.; Wragg, A.B.; Taylor, C.G.P.; Williams, N.H.; Ward, M.D.; Metherell, A. Catalysis in a Cationic Coordination Cage Using a Cavity-Bound Guest and Surface-Bound Anions: Inhibition, Activation, and Autocatalysis. J. Am. Chem. Soc. 2018, 140, 2821-2828. [CrossRef] [PubMed]

32. Rizzuto, F.J.; Wu, W.; Ronson, T.K.; Frantz, D.E. Peripheral Templation Generates an MII 6L4 Guest-Binding Capsule. Angew. Chem. Int. Ed. 2016, 55, 7958-7962. [CrossRef] [PubMed] 
33. Sgarlata, C.; Mugridge, J.S.; Pluth, M.D.; Tiedemann, B.E.F.; Zito, V.; Arena, G.; Raymond, K.N. External and Internal Guest Binding of a Highly Charged Supramolecular Host in Water: Deconvoluting the Very Different Thermodynamics. J. Am. Chem. Soc. 2010, 132, 1005-1009. [CrossRef] [PubMed]

34. Cullen, W.; Misuraca, M.C.; Hunter, C.A.; Williams, N.H.; Ward, M.D. Highly efficient catalysis of the Kemp elimination in the cavity of a cubic coordination cage. Nat. Chem. 2016, 8, 231-236. [CrossRef] [PubMed]

35. Taylor, C.G.P.; Metherell, A.J.; Argent, S.P.; Ashour, F.M.; Williams, N.H.; Ward, M.D. Coordination-Cage-Catalysed Hydrolysis of Organophosphates: Cavity- or Surface-Based? Chem. Eur. J. 2020, 26, 3065-3073. [CrossRef] [PubMed]

36. Mozaceanu, C.; Taylor, C.G.P.; Piper, J.R.; Argent, S.P.; Ward, M.D. Catalysis of an Aldol Condensation Using a Coordination Cage. Chemistry 2020, 2, 22-32. [CrossRef]

37. Taylor, C.G.P.; Argent, S.P.; Ludden, M.D.; Piper, J.R.; Mozaceanu, C.; Barnett, S.A.; Ward, M.D. One Guest or Two? A Crystallographic and Solution Study of Guest Binding in a Cubic Coordination Cage. Chem. Eur. J. 2020, 26, 3054-3064. [CrossRef]

38. Tidmarsh, I.S.; Faust, T.; Adams, H.; Harding, L.P.; Russo, L.; Clegg, W.; Ward, M.D. Octanuclear Cubic Coordination Cages. J. Am. Chem. Soc. 2008, 130, 15167-15175. [CrossRef]

39. Piper, J.R.; Cletheroe, L.; Taylor, C.G.P.; Metherell, A.; Weinstein, J.A.; Sazanovich, I.V.; Ward, M.D. Photoinduced energy- and electron-transfer from a photoactive coordination cage to bound guests. Chem. Commun. 2017, 53, 408-411. [CrossRef]

40. Train, J.S.; Wragg, A.B.; Auty, A.J.; Metherell, A.; Chekulaev, D.; Taylor, C.G.P.; Argent, S.P.; Weinstein, J.A.; Ward, M.D. Photophysics of Cage/Guest Assemblies: Photoinduced Electron Transfer between a Coordination Cage Containing Osmium(II) Luminophores, and Electron-Deficient Bound Guests in the Central Cavity. Inorg. Chem. 2019, 58, 2386-2396. [CrossRef]

41. Spartan'18, Version 1; Wavefunction Inc.: Irvine, CA, USA, 2018.

42. Allan, D.R.; Nowell, H.; Barnett, S.A.; Warren, M.R.; Wilcox, A.; Christensen, J.; Saunders, L.K.; Peach, A.; Hooper, M.T.; Zaja, L.; et al. A Novel Dual Air-Bearing Fixed- $\chi$ Diffractometer for Small-Molecule Single-Crystal X-ray Diffraction on Beamline I19 at Diamond Light Source. Crystals 2017, 7, 336. [CrossRef]

43. Johnson, N.T.; Waddell, P.; Clegg, W.; Probert, M. Remote Access Revolution: Chemical Crystallographers Enter a New Era at Diamond Light Source Beamline I19. Crystals 2017, 7, 360. [CrossRef]

44. Inokuma, Y.; Yoshioka, S.; Ariyoshi, J.; Arai, T.; Hitora, Y.; Takada, K.; Matsunaga, S.; Rissanen, K.; Fujita, M. $\mathrm{X}$-ray analysis on the nanogram to microgram scale using porous complexes. Nature 2013, 495, 461-466. [CrossRef] [PubMed]

45. Hoshino, M.; Khutia, A.; Xing, H.; Inokuma, Y.; Fujita, M. The crystalline sponge method updated. IUCrJ 2016, 3, 139-151. [CrossRef] [PubMed]

46. Shimizu, T.; Isono, H.; Yasui, M.; Iwasaki, F.; Kamigata, N. Solid state optical activity of dichalcogenides: Isolation by chiral crystallization and determination of absolute configuration. Org. Lett. 2001, 3, 3639-3641. [CrossRef]

47. Metherell, A.J.; Ward, M.D. Geometric isomerism in coordination cages based on tris-chelate vertices: A tool to control both assembly and host/guest chemistry. Dalton Trans. 2016, 45, 16096-16111. [CrossRef]

48. Rebek, J.J. Molecular Behavior in Small Spaces. Acc. Chem. Res. 2009, 42, 1660-1668. [CrossRef]

49. Mecozzi, S.; Rebek, J.J. The 55 \% Solution: A Formula for Molecular Recognition in the Liquid State. Chem. Eur. J. 1998, 4, 1016-1022. [CrossRef]

50. Puttreddy, R.; Beyeh, N.K.; Kalenius, E.; Ras, R.H.A.; Rissanen, K. 2-Methylresorcinarene: A very high packing coefficient in a mono-anion based dimeric capsule and the X-ray crystal structure of the tetra-anion. Chem. Commun. 2016, 52, 8115-8118. [CrossRef]

51. Roos, G.; De Proft, F.; Geerlings, P. Electron Capture by the Thiyl Radical and Disulfide Bond: Ligand Effects on the Reduction Potential. Chem. Eur. J. 2013, 19, 5050-5060. [CrossRef]

52. Taylor, C.G.P.; Piper, J.R.; Ward, M.D. Binding of chemical warfare agent simulants as guests in a coordination cage: Contributions to binding and a fluorescence-based response. Chem. Commun. 2016, 52, 6225-6228. [CrossRef] [PubMed]

(C) 2020 by the authors. Licensee MDPI, Basel, Switzerland. This article is an open access article distributed under the terms and conditions of the Creative Commons Attribution (CC BY) license (http://creativecommons.org/licenses/by/4.0/). 